\title{
Transcutaneous carbon dioxide attenuates impaired oxidative capacity in skeletal muscle in hyperglycemia model
}

\author{
Tomohiro Matsumoto ${ }^{1}$, Masayuki Tanaka ${ }^{2}$, Ryosuke Nakanishi ${ }^{3}$, Miho Takuwa ${ }^{1}$, Takumi \\ Hirabayashi $^{1}$, Kohei Ono ${ }^{1}$, Takuya Ikeji ${ }^{1}$, Noriaki Maeshige ${ }^{1}$, Yoshitada Sakai ${ }^{4}$, Toshihiro \\ Akisue $^{1}$, Hiroyo Kondo ${ }^{5}$, Akihiko Ishihara ${ }^{6}$ and Hidemi Fujino ${ }^{1}$ \\ ${ }^{1}$ Department of Rehabilitation Science, Kobe University Graduate School of Health Sciences, Suma-ku, Kobe-shi, Hyogo, Japan \\ ${ }^{2}$ Department of Physical Therapy, Faculty of Human Sciences, Osaka University of Human Sciences, Settsu-shi, Osaka, Japan \\ ${ }^{3}$ Department of Rehabilitation, Kobe international University, Higashinada-ku, Hyogo, Japan \\ ${ }^{4}$ Division of Rehabilitation Medicine, Kobe University Graduate School of Medicine, Kobe, Japan \\ ${ }^{5}$ Department of Food Science and Nutrition, Nagoya Women's University, Nagoya, Mizuho-ku, Nagoya-shi, Aichi, Japan \\ ${ }^{6}$ Laboratory of Cell Biology and Life Science, Graduate School of Human and Environmental Studies, Kyoto University, \\ Sakyo-ku, Kyoto-shi, Kyoto, Japan
}

\begin{abstract}
Hyperglycemia impairs oxidative capacity in skeletal muscle. Muscle oxidative capacity is regulated by peroxisome proliferator-activated receptor- $\gamma$ co-activator-1 $\alpha$ (PGC-1 $\alpha$ ). Transcutaneous carbon dioxide $\left(\mathrm{CO}_{2}\right)$ enhances PGC-1a expression in skeletal muscle. Therefore, the aim of this study was to clarify the effects of $\mathrm{CO}_{2}$ therapy on muscle oxidative capacity impaired by streptozotocin (STZ)induced hyperglycemia. Eight-week-old male Wistar rats were randomly divided into 4 groups: control, $\mathrm{CO}_{2}$ treatment, STZ-induced hyperglycemia, and STZ-induced hyperglycemia treated with $\mathrm{CO}_{2}$. STZinduced hyperglycemia resulted in a decrease of muscle oxidative capacity and decreased PGC-1 $\alpha$ and cytochrome c oxidase subunit 4 (COX-4) expression levels; while, application of transcutaneous $\mathrm{CO}_{2}$ attenuated this effect, and enhanced the expression levels of endothelial nitric oxide synthesis (eNOS). These results indicate that transcutaneous $\mathrm{CO}_{2}$ improves impaired muscle oxidative capacity via enhancement of eNOS and PGC-1a-related signaling in the skeletal muscle of rats with hyperglycemia.
\end{abstract}

Key words: Carbon dioxide - Muscle oxidative capacity — Hyperglycemia

\begin{abstract}
Abbreviations: cGMP, cyclic guanosine monophosphate; COX-4, cytochrome c oxidase subunit 4; CS, citrate synthase; eNOS, endothelial nitric oxide synthesis; GAPDH, glyceraldehyde-3-phosphate dehydrogenase; PBST, phosphate-buffered saline with $0.1 \%$ Tween 20 ; PGC-1a, peroxisome proliferator-activated receptor- $\gamma$ co-activator-1 $\alpha$; SIRT1, sirtuin 1 ; STZ, streptozotocin.
\end{abstract}

\section{Introduction}

Hyperglycemia induces widespread tissue dysfunction and deleterious complications (Blake and Trounce 2014). Especially, hyperglycemia impairs not only muscle protein synthesis but also oxidative capacity in the skeletal muscle (Py et al. 2002; Frier et al. 2008; Fortes et al. 2015; Ono et

Correspondence to: Hidemi Fujino, Department of Rehabilitation Science, Kobe University Graduate School of Health Sciences, 7-10-2 Tomogaoka, Suma-Ku, Kobe 654-0142, Japan

E-mail: fujino@phoenix.kobe-u.ac.jp al. 2015). Muscle oxidative capacity is an important factor determining exercise capacity (Adams and Schuler 2011). It is critically regulated by mitochondrial function represented by adenosine triphosphate synthesis through the tricarboxylic acid cycle. Muscle oxidative capacity depends on mitochondrial enzymatic activity and biogenesis (Short et al. 2003; White and Schenk 2012), both of which are decreased by hyperglycemia in diabetes (Patti et al. 2003; Boushel et al. 2007; Fujimaki and Kuwabara 2017; Wang et al. 2018), leading to the decrement of exercise capacity. Therefore, attenuation of hyperglycemia-induced impairment of muscle oxidative capacity is important to maintain exercise capacity. 
Peroxisome proliferator-activated receptor- $\gamma$ co-activator$1 \alpha(\mathrm{PGC}-1 \alpha)$ is known as a master regulator of oxidative capacity in the skeletal muscle (Wende et al. 2005; Calvo et al. 2008; Wenz et al. 2009; Tadaishi et al. 2011), and regulates mitochondrial enzymatic activity and biogenesis (Ventura-Clapier et al. 2008). Indeed, in a previous study, PGC-1 a transgenic mice showed an increase in muscle oxidative capacity (Lin et al. 2002). In addition, endurance exercise induced an increase in muscle oxidative capacity via an increase in PGC-1 a expression (Russell et al. 2003; Geng et al. 2010). These reports strongly suggest that PGC-1 $\alpha$ plays a key role in enhancing muscle oxidative capacity. On the other hand, a decrease in PGC-1a expression has been shown to lower muscle oxidative capacity (Leone et al. 2005; Vainshtein et al. 2015). It has been reported that low muscle oxidative capacity in diabetes is associated with decreased PGC-1 a expression (Nagatomo et al. 2011; Wang et al. 2018). Therefore, it would be beneficial to attenuate the decrease in PGC-1a expression in order to suppress the decline of muscle oxidative capacity due to hyperglycemia.

Physical exercise is a principal method to improve low muscle oxidative capacity in diabetes (Lumb 2014). However, it is physically difficult for some diabetic patients due to their complications and exercise intolerance. Therefore, it is necessary to develop an alternative treatment, which is effective even for diabetic patients with exercise intolerance. Carbon dioxide $\left(\mathrm{CO}_{2}\right)$ therapy has long been used in Europe as an effective treatment for cardiac disease and skin lesions (Riggs 1960; Goodman et al. 1975; Wells 1999). Exposure to $\mathrm{CO}_{2}$ elevates blood flow and microcirculation in many tissues as well as partially increases $\mathrm{O}_{2}$ pressure in the local tissues, a phenomenon known as the Bohr effect (Riggs 1960; Wells 1999; Jensen 2004; Izumi et al. 2015). Also, it is well known that $\mathrm{CO}_{2}$ therapy induces peripheral vasodilation, thereby increasing tissue blood flow (Hartmann et al. 1997; Sakai et al. 2011). The transfer of $\mathrm{CO}_{2}$ across the skin might have beneficial local vasomotor effects without causing systemic hemodynamic modifications (Savin et al. 1995). In addition, the effects of $\mathrm{CO}_{2}$-enriched water on subcutaneous microcirculation are regulated by peripheral vasodilation, which results from increased parasympathetic and decreased sympathetic nerve activity (Toriyama et al. 2002). Together, these reports indicate that $\mathrm{CO}_{2}$ therapy has a positive impact on microcirculation. A blood flow-induced mechanical factor enhances the expression level of endothelial nitric oxide synthesis (eNOS) in vascular endothelial cells (Harrison et al. 1996; Fleming and Busse 2003). eNOS is one of three NOS isozymes, which plays a major role in many physiological functions, such as regulating vascular tone (Huang et al. 1995; Duplain et al. 2001) and insulin sensitivity (Vincent et al. 2003). Additionally, nitric oxide synthesized by eNOS can increase PGC-1a protein expression in skeletal muscle via activation of cyclic guanosine monophosphate (cGMP) and consequently promote mitochondrial biogenesis and function (Nisoli et al. 2003, 2004; Le Gouill et al. 2007; Ventura-Clapier et al. 2008; Lira et al. 2010). On the other hand, it has been reported that application of $\mathrm{CO}_{2}$ therapy up-regulates eNOS and cGMP expression in skeletal muscle via an increase in blood flow (Irie et al. 2005; Izumi et al. 2015). Moreover, the expression of positive regulators of oxidative capacity, including PGC-1 $\alpha$ and sirtuin1 (SIRT1) is enhanced by transcutaneous application of $\mathrm{CO}_{2}$ therapy (Oe et al. 2011). These results raise the possibility that transcutaneous $\mathrm{CO}_{2}$ might enhance PGC-1a expression via increase in blood flow-induced eNOS signaling. Therefore, we hypothesized that application of transcutaneous $\mathrm{CO}_{2}$ therapy attenuates the impaired muscle oxidative capacity in diabetes via up-regulation of eNOS and PGC-1 1 signaling. In the present study, we investigated the effect of $\mathrm{CO}_{2}$ therapy on muscle oxidative enzymatic activity and protein expression of eNOS, PGC-1 $\alpha$, and cytochrome c oxidase subunit 4 (COX-4) using type 1 diabetes rodent model generated by a single injection of streptozotocin (STZ), a compound that displays a preferential toxicity toward pancreatic $\beta$-cells.

\section{Materials and Methods}

\section{Animals}

Eight-week-old male Wistar rats (Japan SLC, Shizuoka, Japan) were used. These animals were randomly divided into 4 groups: control $\left(\mathrm{CON} / \mathrm{CO}_{2}(-) ; n=5\right), \mathrm{CO}_{2}$ treatment $\left(\mathrm{CON} / \mathrm{CO}_{2}(+) ; n=5\right)$, STZ-induced diabetes $\left(\mathrm{STZ} / \mathrm{CO}_{2}(-)\right.$; $n=5)$, and STZ-induced diabetes treated with $\mathrm{CO}_{2}(\mathrm{STZ} /$ $\left.\mathrm{CO}_{2}(+) ; n=5\right)$. All animals were housed at a temperature of $22 \pm 2^{\circ} \mathrm{C}$ with $12 / 12 \mathrm{~h}$ light/dark cycle and provided standard rodent chow and water ad libitum. Diabetes was induced by a single intravenous injection of $50 \mathrm{mg} / \mathrm{kg} \mathrm{STZ}$ (Wako, Osaka, Japan) dissolved in citrate buffer. The blood glucose levels were measured 2 days after injection, and animals with blood glucose levels more than $250 \mathrm{mg} / \mathrm{dl}$ were used as a model for diabetes. Rats in both the STZ groups were injected with STZ, and the rats in both CON groups were injected with the same volume of citrate buffer. This study was approved by the Institutional Animal Care and Use Committee and carried out according to the Kobe University Animal Experimentation Regulations. All experiments were conducted in accordance with the National Institute of Health Guide for the Care and Use of Laboratory Animals (National Research Council 1996).

\section{Transcutaneous $\mathrm{CO}_{2}$ therapy}

All animals were anesthetized with isoflurane (Wako, Osaka, Japan), and the hair on their hind limbs were shaved. $\mathrm{CO}_{2}$ hydrogel, which enhances transcutaneous $\mathrm{CO}_{2}$ absorption (NeoChemir Inc Kobe, Japan) as previously described (Oe et 
al. 2011), was applied on their hind limbs without anesthesia. The $\mathrm{CO}_{2}$ adaptor was attached to the limbs and sealed. In the $\mathrm{CON} / \mathrm{CO}_{2}(+)$ and $\mathrm{STZ} / \mathrm{CO}_{2}(+)$ groups, $100 \% \mathrm{CO}_{2}$ gas (Mizushima Sanso, Kobe, Japan) was administered into the adaptor for $30 \mathrm{~min}$, as previously described (Oe et al. 2011). This treatment was started from 5 days after injection of STZ and performed 5 times a week for 8 weeks.

\section{Fasting blood glucose}

After a fasting period of $12 \mathrm{~h}$, the blood samples were obtained from the caudal vein. The blood glucose levels were measured using a portable blood glucose analyzer (Glutest Neo Super; Sanwa Kagaku Kenkyusho Co. Ltd., Nagoya, Japan) and monitored every 2 weeks.

\section{Surgical procedure}

After 8 weeks, rats were anesthetized with sodium pentobarbital (50 mg/kg, i.p.). The soleus muscle was removed and weighed, and then the muscle tissue was rapidly frozen using isopentane cooled in dry ice and stored at $-80^{\circ} \mathrm{C}$ until further biochemical analysis.

\section{Citrate synthase (CS) activity}

The activity of CS, a key mitochondrial enzyme in the tricarboxylic acid cycle, is used as an indicator of oxidative capacity of the skeletal muscle. The sample was homogenized in $10 \mathrm{mM}$ Tris (pH 7.4), $175 \mathrm{mM} \mathrm{KCl}$, and 2 mM EDTA. The homogenates were frozen, thawed thrice, and then centrifuged at 15,000 $\times g$ for $10 \mathrm{~min}$ at $4^{\circ} \mathrm{C}$. The supernatants were collected and used for measuring the CS activity by Srere's method (Srere 1969). Briefly, supernatants were reacted with $5 \mathrm{mM}$ oxaloacetate acid after addition of $100 \mathrm{mM}$ Tris ( $\mathrm{pH} 7.4$ ), $3 \mathrm{mM}$ acetylCoA, and $1 \mathrm{mM}$ 5,5'-dithiobis [2-nitrobenzoric acid], and the absorbance was measured at $412 \mathrm{~nm}$ for $5 \mathrm{~min}$.

\section{Western blotting}

Portions (approximately $10 \mathrm{mg}$ ) of each soleus muscle were homogenized in RIPA lysis buffer containing $1 \mathrm{mM} \mathrm{Na}_{3} \mathrm{VO}_{4}$, $1 \mathrm{mM} \mathrm{NaF}$, and protease inhibitor cocktail (1:100, P8340;
Sigma Chemicals, Perth, WA, USA). Total supernatant protein concentrations were determined according to Bradford method using a protein assay kit (Bradford 1976) (Bio-Rad Laboratories, Hercules, CA, USA) before loading onto either 7.5 or $15 \%$ sodium dodecyl sulfate-polyacrylamide gels. Proteins were blotted onto polyvinylidene difluoride membranes, which were then blocked for $1 \mathrm{~h}$ with $5 \%$ skimmed milk in phosphate-buffered saline with $0.1 \%$ Tween 20 (PBST). Membranes were incubated with antibodies against PGC-1a (1:200 in PBST, sc-13067; Santa Cruz Biotechnology, Santa Cruz, CA, USA), COX-4 (1:1000 in PBST, \#4850; Cell Signaling Technology), or eNOS (1:1000 in PBST, \#5880; Cell Signaling Technology) overnight at $4^{\circ} \mathrm{C}$ and then incubated in a solution with horseradish peroxidase-conjugated anti-mouse or rabbit secondary antibody (1:1000 in PBST; GE, Healthcare, Waukesha, WI, USA) for $1 \mathrm{~h}$. Proteins were detected using EzWestLumi Plus kit (ATTO, Tokyo, Japan). Finally, images were analyzed with an LAS-1000 (Fujifilm, Tokyo, Japan) using a chemiluminescent image analyzer and quantified using the Multi-Gauge Image Analysis Software program (Fujifilm) against a relative concentration of GAPDH (1:1000 in PBST, \#97166; Cell Signaling Technology) as an internal control.

\section{Statistical analysis}

All data are presented as mean \pm standard error of mean (SEM). The differences were assessed by two-way analysis of variance (ANOVA) followed by Tukey's post hoc test. All data of time-dependent changes of blood glucose levels were assessed by two-way repeated measured ANOVA followed by Tukey's post hoc test. Results were deemed statistically significant at $p<0.05$.

\section{Results}

\section{Body mass and soleus muscle mass}

There was no significant difference in body mass and muscle mass between the $\mathrm{STZ} / \mathrm{CO}_{2}(-)$ and $\mathrm{STZ} / \mathrm{CO}_{2}(+)$, and the $\mathrm{CON} / \mathrm{CO}_{2}(-)$ and $\mathrm{CON} / \mathrm{CO}_{2}(+)$ groups, respectively. The mean body mass and soleus muscle mass were significantly decreased due to induction of hyperglycemia (8 weeks) (Table 1).

Table 1. Body mass and absolute soleus muscle mass

\begin{tabular}{|c|c|c|c|c|}
\hline & \multicolumn{2}{|c|}{$\mathrm{CON}$} & \multicolumn{2}{|c|}{ STZ } \\
\hline & $\mathrm{CO}_{2}(-)$ & $\mathrm{CO}_{2}(+)$ & $\mathrm{CO}_{2}(-)$ & $\mathrm{CO}_{2}(+)$ \\
\hline Body mass (g) & $320.4 \pm 8.0$ & $320.0 \pm 10.4$ & $217.2 \pm 19.9^{*}$ & $220.4 \pm 16.0^{*}$ \\
\hline Muscle mass (g) & $122.8 \pm 4.6$ & $126.4 \pm 5.0$ & $90.0 \pm 7.3^{*}$ & $88.0 \pm 7.0^{*}$ \\
\hline
\end{tabular}

Main effects of STZ were assessed by two-way ANOVA. $p<0.05$ is considered statistically significant. Values are presented as mean \pm SEM. ${ }^{*}$ significantly different from CON with same intervention, at $p<0.05$. CON, control, STZ, streptozotocin. 


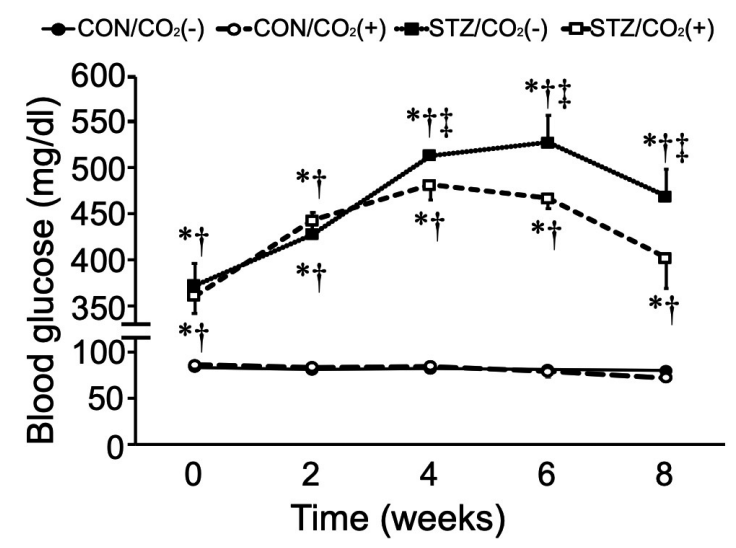

Figure 1. Time-dependent effects of streptozotocin (STZ) and transcutaneous $\mathrm{CO}_{2}$ on fasting blood glucose levels. Values are presented as mean \pm SEM (two-way repeated measured ANOVA). ${ }^{*} p<0.05$ vs. CON group, $\dagger p<0.05$ vs. $\mathrm{CO}_{2}$ group; $\ddagger p<0.05$ vs. STZ group. CON, control.

\section{Fasting blood glucose}

Figure 1 shows the time-dependent change of fasting blood glucose levels for 8 weeks. There was no significant difference in blood glucose levels between the $\mathrm{CON} / \mathrm{CO}_{2}(-)$ and CON/ $\mathrm{CO}_{2}(+)$ groups. The blood glucose levels were significantly higher in both STZ groups compared to those in both CON groups, and lower in $\mathrm{STZ} / \mathrm{CO}_{2}(+)$ group compared to those in $\mathrm{STZ} / \mathrm{CO}_{2}(-)$ group at a point in 4,6 , and 8 weeks after the start of the experiment.

\section{CS activity}

There was no significant difference in CS activity between both the CON groups (Figure 2). CS activity was significantly lower in $\mathrm{STZ} / \mathrm{CO}_{2}(-)$ group than that in $\mathrm{CON} / \mathrm{CO}_{2}(-)$ group, and higher in $\mathrm{STZ} / \mathrm{CO}_{2}(+)$ group than that in STZ/ $\mathrm{CO}_{2}(-)$ group.

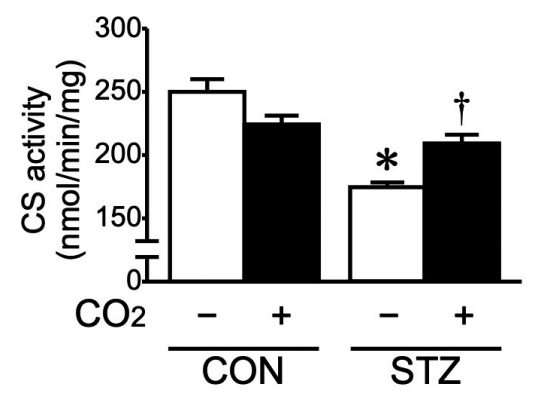

Figure 2. CS activity in the soleus muscle. Values are presented as mean \pm SEM (two-way ANOVA. * and $\dagger$ significantly different from $\mathrm{CON}$ with same intervention and $\mathrm{CO}_{2}(-) v s$. $\mathrm{CO}_{2}(+)$, respectively, at $p<0.05$. CS, citrate synthase; CON, control. STZ, streptozotocin.
Protein expression levels of PGC-1 $\alpha, C O X-4$, and eNOS

Representative images of Western blots for PGC-1a, COX-4, and eNOS expression in the soleus muscle are shown in Figure 3. There were no significant differences in the protein content of PGC-1a, COX- 4 and eNOS between both the CON groups. The protein level of eNOS was significantly higher in the STZ/CO $\mathrm{CO}_{2}(+)$ group than that in the STZ/CO 2 (-) group. The protein levels of PGC-1 $\alpha$ and COX-4 were significantly lower in the $\mathrm{STZ} / \mathrm{CO}_{2}(-)$ group than those in the $\mathrm{CON} / \mathrm{CO}_{2}(-)$ group, but significantly higher in the STZ/CO $\mathrm{CO}_{2}(+)$ group than those in the STZ/ $\mathrm{CO}_{2}(-)$ group.

\section{Discussion}

The novel finding of the present study was that application of transcutaneous $\mathrm{CO}_{2}$ therapy attenuated the decrease in CS activity in the skeletal muscle of rats with STZ-induced hyperglycemia. Furthermore, the protein expression levels of eNOS, PGC-1, and COX-4 were higher in the STZ/CO $(+)$ group compared with those in the STZ/CO $\mathrm{CO}_{2}(-)$ group. These observations indicated that application of transcutaneous $\mathrm{CO}_{2}$ to rats with STZ-induced diabetes improved the impaired muscle oxidative capacity via enhancement of eNOS and PGC-1a-related signaling in hyperglycemic skeletal muscle.

Many studies have reported that PGC-1a is an important regulator of oxidative capacity in skeletal muscle (Zechner et al. 2010; Tadaishi et al. 2011; Kang et al. 2012). In the present study, the activity of CS, an indicator of oxidative capacity, and expression of COX-4, an enzyme of the mitochondrial respiratory chain, in the skeletal muscle were decreased in rats with STZ-induced hyperglycemia (Figure 2), which is consistent with previous reports (Py et al. 2002; Roberts-Wilson et al. 2010; Padrão et al. 2012; Wang et al. 2018). Additionally, the expression level of PGC-1a in the STZ/CO 2 (-) group was significantly decreased compared with that in the $\mathrm{CON} / \mathrm{CO}_{2}(-)$ group (Figure 3 ). Thus, the hyperglycemia-related decline in skeletal muscle oxidative capacity could be due to the down-regulation of PGC-1 1 .

It has been reported that shear stress associated with an increase in blood flow increases the expression level of eNOS (Yang et al. 2013), which can also be achieved by administration of $\alpha_{1}$-adrenergic receptor antagonist prazosin, an inducer of vasodilation (Baum et al. 2004), and exercise (Lloyd et al. 2001; Vassilakopoulos et al. 2003; Egginton 2009; Lee-Young et al. 2010). These reports suggest that blood flow appears to be a strong modulator of eNOS levels. On the other hand, Izumi et al. (2015) showed that $\mathrm{CO}_{2}$ therapy promotes blood flow in the subcutaneous tissues, 
A
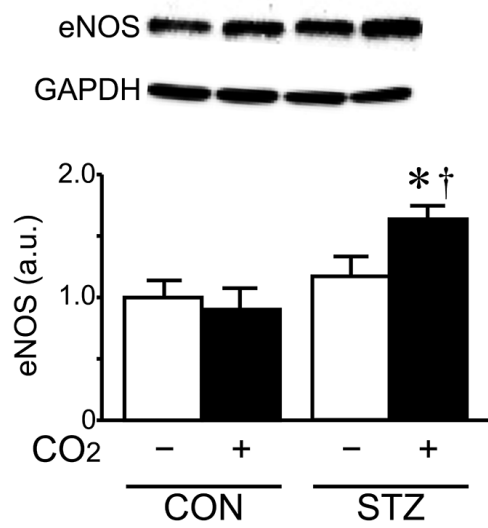

B
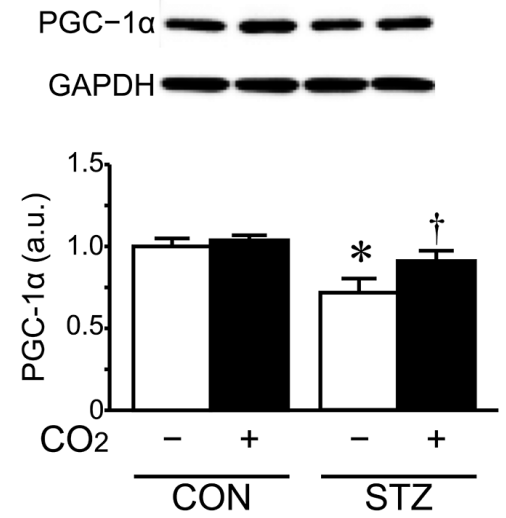

C
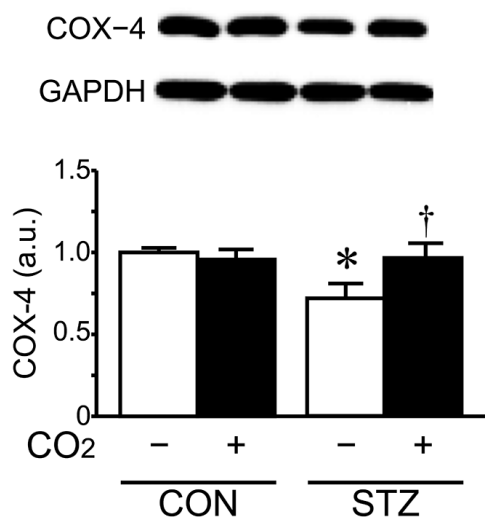

Figure 3. Mean protein expression levels of eNOS (A), PGC-1a (B) and COX-4 (C) in the soleus muscles of each group. The data are expressed as a fold change (a.u.) from the value of the CON group that is set to a value of 1 . The levels of protein expression were normalized to GAPDH level. Values are presented as mean \pm SEM (two-way ANOVA). ${ }^{*}$ and $\dagger$ significantly different from CON with same intervention and $\mathrm{CO}_{2}(-)$ vs. $\mathrm{CO}_{2}(+)$, respectively, at $p<0.05$. eNOS, endothelial nitric oxide synthesis; PGC-1 $\alpha$, peroxisome proliferatoractivated receptor- $\gamma$ co-activator- $1 \alpha$; COX-4, cytochrome $c$ oxidase subunit 4; GAPDH, glyceraldehyde-3-phosphate dehydrogenase; CON, control; STZ, streptozotocin.

and up-regulates the expression of eNOS in the hind limb of ischemic rats. Kindig et al. (1998) showed that STZ-induced hyperglycemia in rat results in a decrease in the proportion of capillaries in the skeletal muscle, due to which the blood flow within the skeletal muscle may be impaired. In the present study, an increase in the expression level of eNOS was observed in the STZ/CO $2(+)$ group, but not in the CON/ $\mathrm{CO}_{2}(+)$ group. Our results, combined with previous findings, suggest the possibility that $\mathrm{CO}_{2}$ therapy might influence eNOS expression only under conditions of reduced blood flow. Therefore, the increased eNOS expression in the STZ/ $\mathrm{CO}_{2}(+)$ group might be associated with enhanced blood flow within the skeletal muscle, consistent with a previous report showing the positive effect of $\mathrm{CO}_{2}$ therapy in a hind limb ischemia model.

eNOS is a key factor for the enhancement of muscle oxidative capacity via up-regulation of PGC-1a expression. In a previous study, application of $\mathrm{CO}_{2}$ to a hind limb ischemia model enhanced eNOS expression in the skeletal muscle (Irie et al. 2005; Izumi et al. 2015). Additionally, application of transcutaneous $\mathrm{CO}_{2}$ to sedentary rats for 12 weeks increased the mRNA level of PGC-1 $1 \alpha$ and SIRT1 and mitochondria number (Oe et al. 2011). Our results showed an increase in the protein expression of PGC1a as well as eNOS by application of transcutaneous $\mathrm{CO}_{2}$ therapy to rats with STZ-induced hyperglycemia. On the other hand, application of transcutaneous $\mathrm{CO}_{2}$ had no influence on the protein expression levels of PGC- $1 \alpha$ and eNOS in the CON/ $\mathrm{CO}_{2}(+)$ group. This result suggested that the increase in expression of PGC-1a in the STZ/CO $2(+)$ group was mediated by increased blood flow and resultant up-regulation of eNOS. Therefore, the effects of transcutaneous $\mathrm{CO}_{2}$ on muscle oxidative capacity in hyperglycemic rats could be involved in the up-regulation of PGC-1 $1 \alpha$ thorough an increase in eNOS expression.

In the present study, application of transcutaneous $\mathrm{CO}_{2}$ decreased the fasting blood glucose levels in rats with STZ-induced hyperglycemia. It has been reported that an increase in PGC-1 a expression improves impaired glucose metabolism (Puigserver 2005). Here, the expression level of PGC-1 1 was increased in the $\mathrm{STZ} / \mathrm{CO}_{2}(+)$ group compared to that in the $\mathrm{STZ} / \mathrm{CO}_{2}(-)$ group. Hence, our results suggest that application of transcutaneous $\mathrm{CO}_{2}$ can improve hyperglycemia via increase of glucose metabolism mediated by increased PGC-1 $\alpha$ expression.

In conclusion, this study demonstrates a novel effect of transcutaneous $\mathrm{CO}_{2}$ on the impaired muscle oxidative capacity of rats with STZ-induced hyperglycemia. Application of transcutaneous $\mathrm{CO}_{2}$ improved hyperglycemia-related decline in muscle oxidative capacity, as shown by an increase in CS activity and increased expression levels of COX4 and PGC-1a, which contributed to the amelioration of hyperglycemia. These results indicate that transcutaneous $\mathrm{CO}_{2}$ therapy can be used to improve hyperglycemia-induced muscle metabolic dysfunction.

Acknowledgment. This study was supported by Grants-in-Aid for Scientific Research from the Japanese Ministry of Education, Culture, Sports, Science and Technology.

Conflict of interest. The authors declare that they have no conflicts of interest. 


\section{References}

Adams V, Anker SD, Schuler G (2011): Muscle metabolism and exercise capacity in cachexia. Curr. Pharm. Des. 35, 3838-3845 https://doi.org/10.2174/138161211798357746

Baum O, Da Silva-Azevedo L, Willerding G, Wöckel A, Planitzer G, Gossrau R, Pries AR, Zakrzewicz A (2004): Endothelial NOS is main mediator for shear stress-dependent angiogenesis in skeletal muscle after prazosin administration. Am. J. Physiol. Heart Circ. Physiol. 287, H2300-H2308 https://doi.org/10.1152/ajpheart.00065.2004

Blake R, Trounce IA (2014): Mitochondrial dysfunction and complications associated with diabetes. Biochim. Biophys. Acta 1840, 1404-1412 https://doi.org/10.1016/j.bbagen.2013.11.007

Boushel R, Gnaiger E, Schjerling P, Skovbro M, Kraunsøe R, Dela F (2007): Patients with type 2 diabetes have normal mitochondrial function in skeletal muscle. Diabetologia 50, 790-796 https://doi.org/10.1007/s00125-007-0594-3

Bradford MM (1976): A rapid and sensitive method for the quantitation of microgram quantities of protein utilizing the principle of protein-dye binding. Anal. Biochem. 72, 248-254 https://doi.org/10.1016/0003-2697(76)90527-3

Calvo JA, Daniels TG, Wang X, Paul A, Lin J, Spiegelman BM, Stevenson SC, Rangwala SM (2008): Muscle-specific expression of PPARgamma coactivator-1alpha improves exercise performance and increases peak oxygen uptake. J. Appl. Physiol. 104, 1304-1312 https://doi.org/10.1152/japplphysiol.01231.2007

Duplain H, Burcelin R, Sartori C, Cook S, Egli M, Lepori M, Vollenweider P, Pedrazzini T, Nicod P, Thorens B, Scherrer U (2001): Insulin resistance, hyperlipidemia, and hypertension in mice lacking endothelial nitric oxide synthase. Circulation 104, 342-345 https://doi.org/10.1161/01.CIR.104.3.342

Egginton S (2009): Invited review: activity-induced angiogenesis. Pflugers Arch. 457, 963-977 https://doi.org/10.1007/s00424-008-0563-9

Fleming I, Busse R (2003): Molecular mechanisms involved in the regulation of the endothelial nitric oxide synthase. Am. J. Physiol. Integr. Comp. Physiol. 284, R1-R12 https://doi.org/10.1152/ajpregu.00323.2002

Fortes MA, Pinheiro, CH, Guimarães-Ferreira L, Vitzel KF, Vasconcelos DA, Curi R (2015): Overload-induced skeletal muscle hypertrophy is not impaired in STZ-diabetic rats. Physiol. Rep. 3, e12457 https://doi.org/10.14814/phy2.12457

Frier BC, Noble EG, Locke M (2008): Diabetes-induced atrophy is associated with a muscle-specific alteration in NF- $\kappa \mathrm{B}$ activation and expression. Cell Stress Chaperones 13, 287-296 https://doi.org/10.1007/s12192-008-0062-0

Fujimaki S, Kuwabara T (2017): Diabetes-induced dysfunction of mitochondria and stem cells in skeletal muscle and the nervous system. Int. J. Mol. Sci. 2017, 18 https://doi.org/10.3390/ijms18102147

Geng T, Li P, Okutsu M, Yin X, Kwek J, Zhang M, Yan Z (2010): PGC-1 $\alpha$ plays a functional role in exercise-induced mitochondrial biogenesis and angiogenesis but not fiber-type transfor- mation in mouse skeletal muscle. Am. J. Physiol. Cell Physiol. 298, C572-C579

https://doi.org/10.1152/ajpcell.00481.2009

Goodman M, Moore GW, Matsuda G (1975): Darwinian evolution in the genealogy of haemoglobin. Nature 253, 603-608 https://doi.org/10.1038/253603a0

Harrison DG, Sayegh H, Ohara Y, Inoue N, Venema RC (1996): Regulation of expression of the endothelial cell nitric oxide synthase. Clin. Exp. Pharmacol. Physiol. 23, 251-255 https://doi.org/10.1111/j.1440-1681.1996.tb02606.x

Hartmann BR, Bassenge E, Pittler M (1997): Effect of carbon dioxide-enriched water and fresh water on the cutaneous microcirculation and oxygen tension in the skin of the foot. Angiology 48, 337-343 https://doi.org/10.1177/000331979704800406

Huang PL, Huang Z, Mashimo H, Bloch KD, Moskowitz MA, Bevan JA, Fishman MC (1995): Hypertension in mice lacking the gene for endothelial nitric oxide synthase. Nature $377,239-242$

https://doi.org/10.1038/377239a0

Irie $\mathrm{H}$, Tatsumi $\mathrm{T}$, Takamiya $\mathrm{M}$, Zen $\mathrm{K}$, Takahashi $\mathrm{T}$, Azuma $\mathrm{A}$, Tateishi K, Nomura T, Hayashi H, Nakajima N, et al. (2005): Carbon dioxide-rich water bathing enhances collateral blood flow in ischemic hindlimb via mobilization of endothelial progenitor cells and activation of NO-cGMP system. Circulation 111, 1523-1529 https://doi.org/10.1161/01.CIR.0000159329.40098.66

Izumi Y, Yamaguchi T, Yamazaki T, Yamashita N, Nakamura Y, Shiota M, Tanaka M, Sano S, Osada-Oka M, Shimada K, et al. (2015): Percutaneous carbon dioxide treatment using a gas mist generator enhances the collateral blood flow in the ischemic hindlimb. J. Atheroscler. Thromb. 22, 38-51 https://doi.org/10.5551/jat.23770

Jensen FB (2004): Red blood cell pH, the Bohr effect, and other oxygenation-linked phenomena in blood $\mathrm{O} 2$ and $\mathrm{CO} 2$ transport. Acta Physiol. Scand. 182, 215-227 https://doi.org/10.1111/j.1365-201X.2004.01361.x

Kang C, Li Ji L (2012): Role of PGC-1 a signaling in skeletal muscle health and disease. Ann. N. Y. Acad. Sci. 1271, 110-117 https://doi.org/10.1111/j.1749-6632.2012.06738.x

Kindig CA, Sexton WL, Fedde MR, Poole DC (1998): Skeletal muscle microcirculatory structure and hemodynamics in diabetes. Respir. Physiol. 111, 163-175 https://doi.org/10.1016/S0034-5687(97)00122-9

Lee-Young RS, Ayala JE, Hunley CF, James FD, Bracy DP, Kang L, Wasserman DH (2010): Endothelial nitric oxide synthase is central to skeletal muscle metabolic regulation and enzymatic signaling during exercise in vivo. Am. J. Physiol. Regul. Integr. Comp. Physiol. 298, R1399-R1408 https://doi.org/10.1152/ajpregu.00004.2010

Le Gouill E, Jimenez M, Binnert C, Jayet PY, Thalmann S, Nicod P, Scherrer U, Vollenweider P (2007): Endothelial nitric oxide synthase (eNOS) knockout mice have defective mitochondrial beta-oxidation. Diabetes 56, 2690-2696 https://doi.org/10.2337/db06-1228

Leone TC, Lehman JJ, Finck BN, Schaeffer PJ, Wende AR, Boudina S, Courtois M, Wozniak DF, Sambandam N, Bernal-Mizrachi C, et al. (2005): PGC-1 a deficiency causes multi-system energy 
metabolic derangements: muscle dysfunction, abnormal weight control and hepatic steatosis. PLoS Biol. 3, e101 https://doi.org/10.1371/journal.pbio.0030101

Lin J, Wu H, Tarr PT, Zhang CY, Wu Z, Boss O, Michael LF, Puigserver P, Isotani E, Olson EN, et al. (2002): Transcriptional coactivator PGC-1 $a$ drives the formation of slow-twitch muscle fibres. Nature 418, 797-801 https://doi.org/10.1038/nature00904

Lira VA, Brown DL, Lira AK, Kavazis AN, Soltow QA, Zeanah EH, Criswell DS (2010): Nitric oxide and AMPK cooperatively regulate PGC-1 $a$ in skeletal muscle cells. J. Physiol. 588, 3551-3566 https://doi.org/10.1113/jphysiol.2010.194035

Lloyd PG, Yang HT, Terjung RL (2001): Arteriogenesis and angiogenesis in rat ischemic hindlimb: role of nitric oxide. Am. J. Physiol. Heart Circ. Physiol. 281, H2528-H2538 https://doi.org/10.1152/ajpheart.2001.281.6.H2528

Lumb A (2014): Diabetes and exercise. Clin. Med. (Lond) 14, 673-676 https://doi.org/10.7861/clinmedicine.14-6-673

Nagatomo F, Fujino H, Kondo H, Gu N, Takeda I, Ishioka N, Tsuda K, Ishihara A (2011): PGC-1a mRNA level and oxidative capacity of the plantaris muscle in rats with metabolic syndrome, hypertension, and type 2 diabetes. Acta Histochem. Cytochem. 44, 73-80 https://doi.org/10.1267/ahc.10041

Nisoli E, Clementi E, Paolucci C, Cozzi V, Tonello C, Sciorati C, Bracale R, Valerio A, Francolini M, et al. (2003): Mitochondrial biogenesis in mammals: the role of endogenous nitric oxide. Science 299, 896-899 https://doi.org/10.1126/science.1079368

Nisoli E, Falcone S, Tonello C, Cozzi V, Palomba L, Fiorani M, Pisconti A, Brunelli S, Cardile A, Francolini M, et al. (2004): Mitochondrial biogenesis by NO yields functionally active mitochondria in mammals. Proc. Natl. Acad. Sci. USA 101, 16507-16512 https://doi.org/10.1073/pnas.0405432101

Oe K, Ueha T, Sakai Y, Niikura T, Lee SY, Koh A, Hasegawa T, Tanaka M, Miwa M, Kurosaka M (2011): The effect of transcutaneous application of carbon dioxide (CO2) on skeletal muscle. Biochem. Biophys. Res. Commun. 407, 148-152 https://doi.org/10.1016/j.bbrc.2011.02.128

Ono T, Takada S, Kinugawa S, Tsutsui H (2015): Curcumin ameliorates skeletal muscle atrophy in type 1 diabetic mice by inhibiting protein ubiquitination. Exp. Physiol. 100, $1052-1063$ https://doi.org/10.1113/EP085049

Padrão AI, Carvalho T, Vitorino R, Alves RM, Caseiro A, Duarte JA, Ferreira R, Amado F (2012): Impaired protein quality control system underlies mitochondrial dysfunction in skeletal muscle of streptozotocin-induced diabetic rats. Biochim. Biophys. Acta 1822, $1189-1197$ https://doi.org/10.1016/j.bbadis.2012.04.009

Patti ME, Butte AJ, Crunkhorn S, Cusi K, Berria R, Kashyap S, Miyazaki Y, Kohane I, Costello M, Saccone R, et al. (2003): Coordinated reduction of genes of oxidative metabolism in humans with insulin resistance and diabetes: Potential role of PGC1 and NRF1. Proc. Natl. Acad. Sci. USA 100, 8466-8471 https://doi.org/10.1073/pnas.1032913100

Puigserver P (2005): Tissue-specific regulation of metabolic pathways through the transcriptional coactivator PGC1-a. Int. J. Obes. (Lond) 29, S5-S9 https://doi.org/10.1038/sj.ijo.0802905

Py G, Lambert K, Milhavet O, Eydoux N, Préfaut C, Mercier J (2002): Effects of streptozotocin-induced diabetes on markers of skeletal muscle metabolism and monocarboxylate transporter 1 to monocarboxylate transporter 4 transporters. Metabolism 51, 807-813

https://doi.org/10.1053/meta.2002.33343

Riggs A (1960): The nature and significance of the Bohr effect in mammalian hemoglobins. J. Gen. Physiol. 43, 737-752 https://doi.org/10.1085/jgp.43.4.737

Roberts-Wilson TK, Reddy RN, Bailey JL, Zheng B, Ordas R, Gooch JL, Price SR (2010): Calcineurin signaling and PGC-1 $\alpha$ expression are suppressed during muscle atrophy due to diabetes. Biochim. Biophys. Acta 1803, 960-967 https://doi.org/10.1016/j.bbamcr.2010.03.019

Russell AP, Feilchenfeldt J, Schreiber S, Praz M, Crettenand A, Gobelet C, Meier CA, Bell DR, Kralli A, Giacobino JP, Dériaz O (2003): Endurance training in humans leads to fiber type-specific increases in levels of peroxisome proliferator-activated receptor- $\gamma$ coactivator- 1 and peroxisome proliferator-activated receptor- $\alpha$ in skeletal muscle. Diabetes 52, 2874-2881 https://doi.org/10.2337/diabetes.52.12.2874

Sakai Y, Miwa M, Oe K, Ueha T, Koh A, Niikura T, Iwakura T, Lee SY, Tanaka M, Kurosaka M (2011): A novel system for transcutaneous application of carbon dioxide causing an ,artificial Bohr effect" in the human body. PLoS One 6, e24137 https://doi.org/10.1371/journal.pone.0024137

Savin E, Bailliart O, Bonnin P, Bedu M, Cheynel J, Coudert J, Martineaud JP (1995): Vasomotor effects of transcutaneous $\mathrm{CO} 2$ in stage II peripheral occlusive arterial disease. Angiology 46, 785-791 https://doi.org/10.1177/000331979504600904

Short KR, Vittone JL, Bigelow ML, Proctor DN, Rizza RA, CoenenSchimke JM, Nair KS (2003): Impact of aerobic exercise training on age-related changes in insulin sensitivity and muscle oxidative capacity. Diabetes 52, 1888-1896 https://doi.org/10.2337/diabetes.52.8.1888

Srere PA (1969): Citrate synthase. Meth. Enzymol. 13, 3-11 https://doi.org/10.1016/0076-6879(69)13005-0

Tadaishi M, Miura S, Kai Y, Kano Y, Oishi Y, Ezaki O (2011): Skeletal muscle-specific expression of PGC-1a-b, an exercise-responsive isoform, increases exercise capacity and peak oxygen uptake. PLoS One 6, e28290 https://doi.org/10.1371/journal.pone.0028290

Toriyama T, Kumada Y, Matsubara T, Murata A, Ogino A, Hayashi H, Nakashima H, Takahashi H, Matsuo H, Kawahara H (2002): Effect of artificial carbon dioxide foot bathing on critical limb ischemia (Fontaine IV) in peripheral arterial disease patients. Int. Angiol. 21, 367-373

Vainshtein A, Desjardins EM, Armani A, Sandri M, Hood DA (2015): PGC-1 $\alpha$ modulates denervation-induced mitophagy in skeletal muscle. Skelet. Muscle 5, 9 https://doi.org/10.1186/s13395-015-0033-y 
Vassilakopoulos T, Deckman G, Kebbewar M, Rallis G, Harfouche R, Hussain SN (2003): Regulation of nitric oxide production in limb and ventilatory muscles during chronic exercise training. Am. J. Physiol. Lung Cell Mol. Physiol. 284, L452-L457 https://doi.org/10.1152/ajplung.00270.2002

Ventura-Clapier R, Garnier A, Veksler V (2008): Transcriptional control of mitochondrial biogenesis: the central role of PGC- $1 \alpha$. Cardiovasc. Res. 79, 208-217 https://doi.org/10.1093/cvr/cvn098

Vincent MA, Barrett EJ, Lindner JR, Clark MG, Rattigan S (2003): Inhibiting NOS blocks microvascular recruitment and blunts muscle glucose uptake in response to insulin. Am. J. Physiol. Endocrinol. Metab. 285, E123-E129 https://doi.org/10.1152/ajpendo.00021.2003

Wang D, Sun H, Song G, Yang Y, Zou X, Han P, Li S (2018): Resveratrol improves muscle atrophy by modulating mitochondrial quality control in STZ-induced diabetic mice. Mol. Nutr. Food Res. 62, e1700941 https://doi.org/10.1002/mnfr.201700941

Wells RM (1999): Evolution of haemoglobin function: molecular adaptations to environment. Clin. Exp. Pharmacol. Physiol. 26, 591-595 https://doi.org/10.1046/j.1440-1681.1999.03091.x

Wende AR, Huss JM, Schaeffer PJ, Gigue V, Kelly DP (2005): PGC-1a coactivates PDK4 gene expression via the orphan nuclear receptor ERRa: a mechanism for transcriptional control of muscle glucose metabolism. Mol. Cell. Biol. 25, 10684-10694 https://doi.org/10.1128/MCB.25.24.10684-10694.2005

Wenz T, Rossi SG, Rotundo RL, Spiegelman BM, Moraes CT (2009): Inceased muscle PGC-1 $\alpha$ expression protects from sarcopenia and metabolic disease during aging. Proc. Natl. Acad. Sci. USA 106, 20405-20410 https://doi.org/10.1073/pnas.0911570106

White AT, Schenk S (2012): NAD+/NADH and skeletal muscle mitochondrial adaptations to exercise. Am. J. Physiol. Endocrinol. Metab. 303, E308-E321 https://doi.org/10.1152/ajpendo.00054.2012

Yang B, Rizzo Y (2013): Shear stress activates eNOS at the endothelial apical surface through $\beta 1$ containing integrins and caveolae. Cell. Mol. Bioeng. 6, 346-354 https://doi.org/10.1007/s12195-013-0276-9

Zechner C, Lai L, Zechner JF, Geng T, Yan Z, Rumsey JW, Collia D, Chen Z, Wozniak DF, Leone TC, Kelly DP (2010): Total skeletal muscle PGC-1 deficiency uncouples mitochondrial derangements from fiber type determination and insulin sensitivity. Cell Metab. 12, 633-642 https://doi.org/10.1016/j.cmet.2010.11.008

Received: August 13, 2018

Final version accepted: December 19, 2018 